\title{
The NCD problem
}

\section{REGIONAL EPIDEMIOLOGICAL INFORMATION}

NCDs cause the majority of premature adult deaths and pose a serious threat to health and

development in the region.

- NCD mortality in the Caribbean is the highest in the Americas.

- On average, people in CARICOM countries have lower life expectancy at birth than those in Central or Latin America, a reversal of the situation that existed 30 to 40 years ago.

- $40 \%$ of NCD deaths occur prematurely, in those under 70, and are potentially preventable.

- Heart attacks, stroke, diabetes and cancers are the leading causes of premature death.

- Hypertension is the leading risk factor for death.

- Diabetes prevalence is double global rates.

- According to surveys conducted in 12 CARICOM countries:

o $10 \%$ to $25 \%$ of adults have diabetes; and

o $20 \%$ to over $50 \%$ suffer from high blood pressure.

- In some countries there are particularly high rates of undiagnosed chronic diseases. For example, $50 \%$ of people in Jamaica do not know they have high blood pressure, 25\% don't know they are diabetic and some $80 \%$ are unaware that they have high cholesterol.

- It is estimated that only 8 of 20 CARICOM countries are on course to meet the World Health Organization's target of a 25\% reduction in premature NCD mortality by 2025 .

- More than 85\% of adults in CARICOM Member States do not meet recommended levels of fruit and vegetable intake.

NCDs: Risk factors

4 Diseases, 4 Modifiable Shared Risk Factors

\begin{tabular}{|c|c|c|c|c|}
\hline & $\begin{array}{l}\text { Tobacco } \\
\text { Use }\end{array}$ & $\begin{array}{l}\text { Unhealthy } \\
\text { diets }\end{array}$ & $\begin{array}{l}\text { Physical } \\
\text { Inactivity }\end{array}$ & $\begin{array}{l}\text { Harmful } \\
\text { Use of } \\
\text { Alcohol }\end{array}$ \\
\hline $\begin{array}{l}\text { Cardio- } \\
\text { vascular }\end{array}$ & & & & \\
\hline Diabetes & & & & \\
\hline Cancer & & & & \\
\hline $\begin{array}{l}\text { Chronic } \\
\text { Respiratory }\end{array}$ & & & & \\
\hline
\end{tabular}
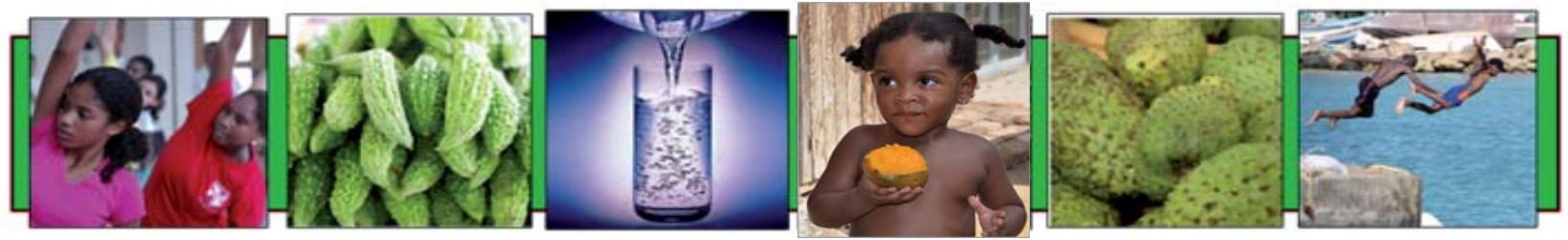
- Women are $60 \%$ more likely to have diabetes than men and twice as likely to be obese. Barbados, Trinidad and Tobago, Dominica and Jamaica are among the top 14 countries in global female obesity.

- Physical inactivity in women is significantly higher than in men. In Barbados 9 out of 10 women do not meet World Health Organization activity recommendations. The rate for men is 6 in 10 .

- Men have lower rates of health service utilisation, worse control of chronic conditions, such as hypertension, and higher death rates from NCDs at every age. For example, men are much more likely to die from cardiovascular disease and diabetes. In Trinidad and Tobago the figure for premature male mortality from this condition was 135 per 100,000; for women a significantly lower 84 per 100,000 (2010).

- Men have higher rates of harmful use of alcohol than women, with 1 in 5 men reporting binge drinking and 10\% - 20\% of men recorded as current tobacco smokers. Rates of tobacco use and alcohol abuse are half or lower in women.

- In several countries the detection and control of high blood pressure is consistently worse in men compared to women.

\section{Children are increasingly at risk of developing NCDs.}

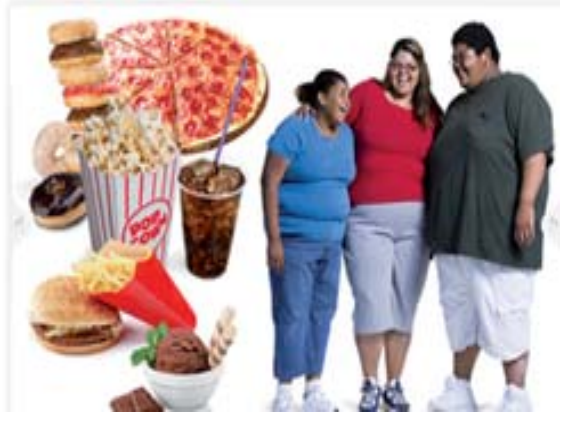

- Childhood obesity exceeds $10 \%$ in 7 of 11 countries with data. $(24 \%$ of girls in the Bahamas are obese).

- This obesity is being driven in part by the increased availability of high-fat, high-sugar fast foods and sugar-sweetened bevarages.

- Studies indicate that in every surveyed CARICOM Member State, less than a third of school children aged 13-15 years get the recommended level of physical activity.

- Alcohol use among 13-15-year-olds exceeds $40 \%$ in 11 out of 20 countries, with tobacco use approaching adult rates.

\section{A broader perspective}

- The risk factors and behaviours that contribute to the NCD epidemic take place within particular social, economic and physical environments.

- We need to ensure that these environments help us to live longer, heathier lives and pursue policy, legislative and fiscal arrangements that encourage better health.

- As a region we can, for example:

o Ban advertising that targets unhealthy, high-fat, high-salt, high-sugar food at children

o Raise taxes on tobacco and alcohol to lower consumption and fund NCD interventions

o Make the Caribbean a trans fat-free and smoke-free zone

o Promote healthy eating and more physical activity in schools

o Create spaces to promote physical activity like bicycle lanes, run/walk/cycle events, boardwalks and ensure that our built environments enable increased physical activity.

For more information and fact sheets visit our website at www.onecaribbeanhealth.org

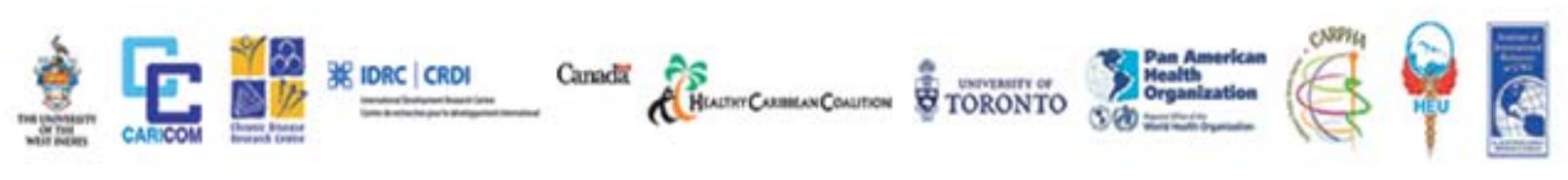

